\title{
Proceedings of the 16th International Conference on Liquid and Amorphous Metals (LAM-16)
}

\author{
Editors: Dirk Holland-Moritz ${ }^{1, *}$ and Florian Kargl $^{1}$ \\ ${ }^{1}$ Institut für Materialphysik im Weltraum, Deutsches Zentrum für Luft- und Raumfahrt (DLR), 51170 \\ Köln, Germany
}

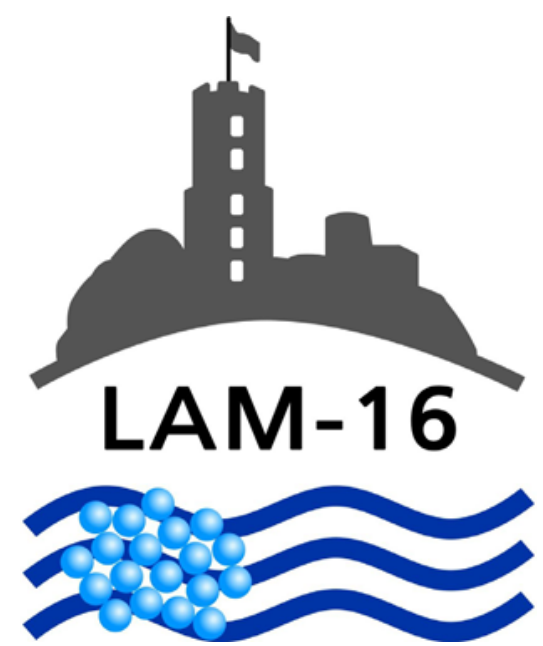

\section{Preface}

The 16th International Conference on Liquid and Amorphous Metals (LAM-16) was held at the town hall of Bonn - Bad Godesberg, Germany, from September 04-09, 2016. It was part of a series of conferences that has a long standing history dating back to the liquids metal conference LM-1 in Brookhaven (1966). The LM-1 was followed by the liquid metals conferences in Tokyo (1972) and Bristol (1976). The scope of the conference series was complemented by topics of amorphous metals in the following LAM conferences held in Grenoble (1980), Los Angeles (1983), Garmisch-Partenkirchen (1986), Kyoto (1989), Wien (1992), Chicago (1995), Dortmund (1998), Yokohama (2001), Metz (2004), Ekaterinburg (2007), Rome (2010) and Beijing (2013). The LAM conferences aim to provide a forum for scientists interested in liquid and amorphous metals in order to discuss recent advances and future directions in this intriguing field of condensed matter physics, chemistry and materials sciences. Apart from papers on metallic systems, the LAM conferences

${ }^{*}$ Corresponding author: dirk.holland-moritz@,dlr.de 
traditionally also welcome contributions on liquid and amorphous semi-conductors as well as on molten salts.

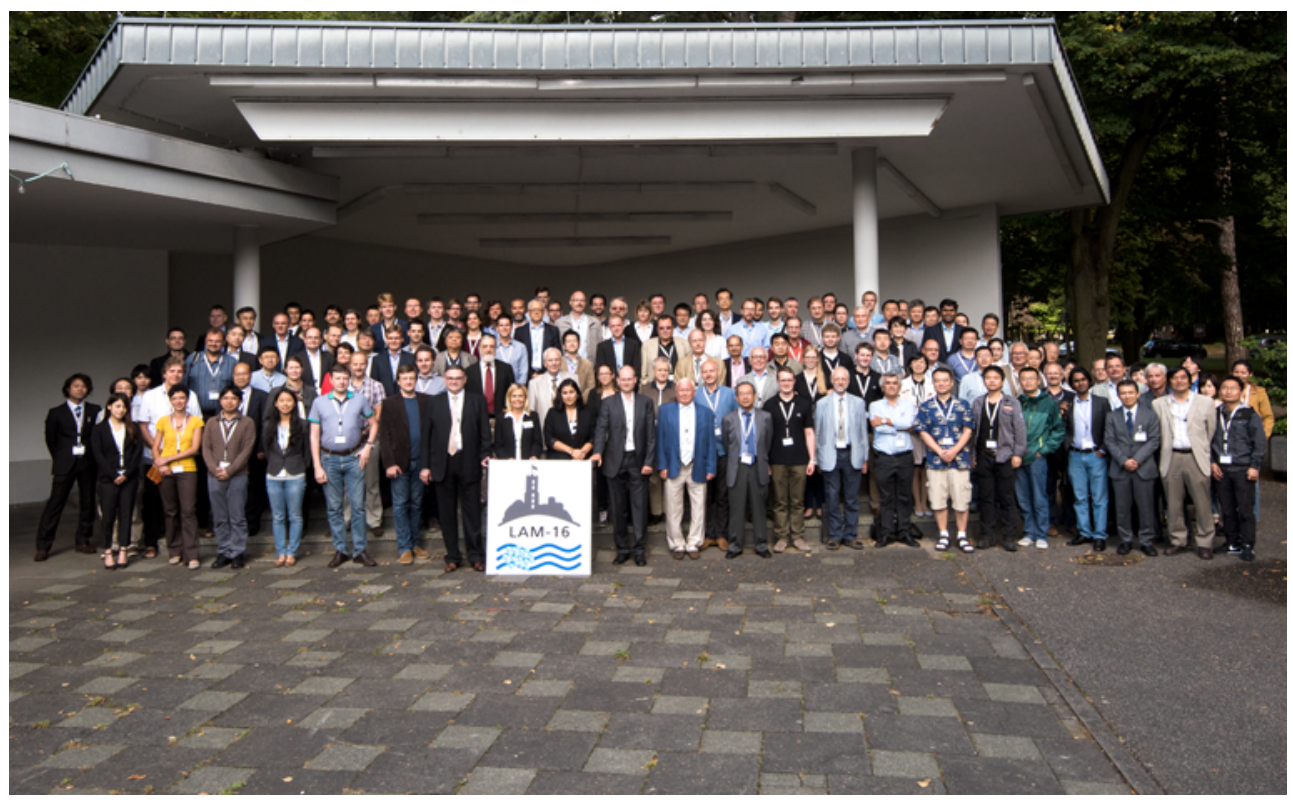

Fig. 1. Participants of the LAM-16 conference gathered at the band-stand of the town-hall of Bonn Bad Godesberg.

135 scientists from 19 different countries, 9 accompanying persons and 3 nonscientific members of the organization team participated in the LAM-16 conference. The conference program comprised 5 plenary talks, 25 invited talks and 72 contributed talks. Different from preceding LAM-conferences the invited and contributed talks were held in parallel sessions in two rooms, allowing for a comparatively large number of talks. Most of the thematically focused sessions were introduced by an invited talk on the topic. Altogether we had 30 oral sessions on the following topics:

- Glass Transition

- Extreme Conditions

- Demixing / Liquid-Liquid Phase Transformations

- Electronic and Magnetic Properties

- Applications / Materials Development

- Structure and Dynamics

- Expanded Liquids / Electronic Properties

- Heat Treatment / Devitrification

- Properties of Metallic Glasses

- Dynamics

- Structure

- Solidification

- Excitations in Liquids and Glasses

- Containerless Processing

- Thermophysical Properties

- Modelling / Simulations

- Structure and Properties of Glasses 
In addition to the oral sessions 48 poster contributions were presented in a vivid poster session on Tuesday evening. The posters were displayed in the foyer of the town-hall during 3 conference days allowing for a view of the posters also during conference breaks. Two young scientists were awarded with a best poster award. The second prize won Ms. M. Sc. Nadège Meyer for her poster entitled 'Shear Viscosity of Liquid Potassium and Cesium: A Simulation Study'. The first prize was awarded to Ms. M. Sc. Beatrix Gonzalez del Rio for her poster entitled 'Orbital-free ab initio molecular dynamics study of the free liquid surface of Sn. From pseudopotential generation to structural and dynamic properties'.

In these conference proceedings 30 papers are collected that provide an overview over the research field of liquid and amorphous metals. The papers have been accepted for publication after a peer-reviewing process. We would like to thank the group of renowned experts that served as referees of the manuscripts for their support and their critical suggestions that helped improving the quality of the papers.

Finally we would like to express our gratitude to the sponsors of the LAM-16 conference: German Aerospace Center (DLR), Deutsche Forschungsgemeinschaft (DFG) and Leybold GmbH. We also would like to thank the LAM committees and the members of the organizing team for their effort that helped making LAM-16 conference a success. 